\title{
Women's experiences of low back pain during pregnancy
}

\author{
Maria João Mota ${ }^{\mathrm{a}, *}$, Mirtha Cardoso ${ }^{\mathrm{b}}$, Andreia Carvalho ${ }^{\mathrm{c}}$, Alda Marques ${ }^{\mathrm{e}}$, Pedro Sá-Couto ${ }^{\mathrm{e}}$ and \\ Sara Demain ${ }^{\mathrm{f}}$ \\ ${ }^{a}$ Association of Parents and Friends of the Person with Mental Disability, Rua Padre Luís Pereira, Portugal \\ ${ }^{\mathrm{b}}$ São Bernardo Clinic, Aveiro, Portugal \\ ${ }^{\mathrm{c}}$ School of Health Technologies of Coimbra, Coimbra, Portugal \\ ${ }^{\mathrm{d}}$ School of Health Sciences, University of Aveiro, Aveiro, Portugal \\ ${ }^{\mathrm{e}}$ Center for Research and Development in Mathematics and Applications, Mathematics Department, University of \\ Aveiro, Aveiro, Portugal \\ ${ }^{\mathrm{f}}$ Faculty of Health Sciences, University of Southampton, Southampton, UK
}

\begin{abstract}
.
OBJECTIVES: This study investigated the self-reported prevalence and impact of low back pain (LBP) during pregnancy in primiparous and multiparous women, and their treatment-seeking rationales and experiences, including their use of physiotherapy.

METHODS: A sample of 105 post-partum women was recruited. All participants answered a questionnaire; women who experienced LBP during pregnancy $(n=71)$ continue in the study and later they were also interviewed. Content analysis, descriptive and inferential statistics were used to analyse the data.

RESULTS: Reports of LBP were common $(n=71 ; 67.6 \%)$ and slightly more frequent in primiparous $(n=40 ; 56.3 \%)$ than multiparous $(n=31 ; 43.7 \%)$ women. Multiparous women with LBP were significantly older $(p<0.001)$ and reported more sleep disturbances $(p=0.026)$ than primiparous women with LBP. LBP prevented women performing their daily activities $(n=$ $41 ; 57.7 \%)$ and worsened with the advance of pregnancy $(n=55 ; 77.5 \%)$, yet 93.0\% $(n=66)$ of these women received no treatment.

CONCLUSION: LBP is a prevalent and important clinical condition affecting the daily life of many pregnant women. Nevertheless, few women seek any treatment and physiotherapy is rarely considered. Given the significant impact on quality of life, health professionals need to be proactive in asking women about LBP.
\end{abstract}

Keywords: Low back pain, pregnancy, multiparous, primiparous, physiotherapy

\section{Introduction}

Low back pain (LBP) is a common condition during pregnancy with a cited prevalence of between $55 \%$ and $78 \%[1-4]$. LBP has a negative impact on women's daily activities, quality of life, and ability to work therefore also affecting national productivity [4]. Despite this pregnancy related LBP is often untreated [1].

* Corresponding author: Maria João Mota, Association of Parents and Friends of the Person with Mental Disability, Rua Padre Luís Pereira, $n^{\circ} 1$, Azurva - Aveiro 3800-737 Eixo, Portugal. Tel.: +351 969197 154; E-mail: mjmm@ua.pt.
The etiology of LBP during pregnancy is multifactorial and frequently associated with biomechanical, hormonal and vascular changes [3]. Reported risk factors for LBP during pregnancy include maternal age [1], socioeconomic class, presence of LBP before pregnancy or during previous pregnancies, heavy work [2], parity, body mass index, family history of LBP, diagnosis of hypermobility and a family history of hypermobility [5].

Given the concerns about the prescription of medication during pregnancy, physical modalities, often provided by physiotherapists, have been recommended as a first line management for LBP during pregnancy. 
Physiotherapy interventions during pregnancy have been shown to be more effective in reducing LBP than usual prenatal care alone [6]. Supervised exercise and water gymnastics carried out during the second half of pregnancy can significantly reduce LBP $[7,12]$ and decrease sick-leave during pregnancy [8]. Shim et al. [9] recommended good posture and regular exercise as a method of reducing LBP. Massage therapy has been shown to be effective for reducing LBP and decreasing levels of anxiety [10]. Carr [11] indicated that the use of orthotheses such as sacroiliac belts can significantly reduce pain and lessen the effects on daily life; however, Vleeming et al. [13] identified no evidence for the use of a pelvic belt as a stand-alone treatment. Transcutaneous electrical nerve stimulation can also be used, but tends to be the last treatment option, when other treatments are not effective [12]. Physiotherapy may therefore potentially prevent and treat LBP during pregnancy, enhance the performance of daily activities and consequently improve pregnant women's quality of life [4]. However, few studies have been conducted in this area and most of them had a high potential for bias, used small samples and did not provide description of treatments, so results must be viewed with caution [6].

Anecdotal evidence suggests that physiotherapy is often not a routine component of ante-natal care. It is therefore unclear what knowledge or views women might have about the role of physiotherapy as a treatment for LBP during pregnancy. There is also little knownedge about the views of those women who have used physiotherapy modalities to treat LBP during pregnancy; their reasons for seeking treatment and their satisfaction with the outcomes.

The aims of this study were: to investigate selfreported prevalence and impact of pregnancy related LBP in primiparous and multiparous women and their treatment seeking rationales and experiences, including their use of physiotherapy.

\section{Methods}

\subsection{Design}

A cross-sectional observation study was carried out in the central region of Portugal. The study received full approval from the Ethics Committees of the primary care centers (Águeda, Vagos and Santa Joana) and of the central hospital (Hospital Infante D. Pedro), Aveiro, Portugal.

\subsection{Sample and measurements}

Recruitment occurred in the three primary care centers and at the Obstetrics service of the Hospital, during the post-natal appointments which occurred $15.3 \pm$ 20.4 days after delivery. Women were included in the study if they were 18 years or older, had given birth within the previous three months, were able to comprehend the Portuguese language and signed the consent forms. Women were excluded if they presented severe hearing, visual or cognitive impairment and previous orthopaedic lesions in the lower back (such as disc herniation or trauma). All women who met the inclusion criteria were informed about the study by a staff member, usually a nurse. Interested participants contacted the researchers and signed the consent forms prior to any data collection.

A total of one hundred and ten post-partum women were invited to participate in this study; five were excluded due to pre-pregnancy low back disc herniation $(n=4)$ and spondyloarthrosis $(n=1)$.

For data collection, a mixed methods approach was used which consisted of a questionnaire and a semistructured qualitative interview. The Assis and Tibúrcio questionnaire [1], which is in Brazilian Portuguese, was piloted with approximately $10 \%$ of the sample (not included in the main study), and minor changes in language made to convert it to European Portuguese. This instrument allowed sample characterization, determination of LBP prevalence (Table 1), and description of LBP in primiparous and multiparous women (Tables 2 and 3). The internal consistency of the European Portuguese version was satisfactory (Cronbach's alpha $=0.65$; (considered moderate consistency) [14]. The interviews were semi-structured with open questions to determine the impact of LBP on women's lives, the reasons why they either sought or did not seek treatment for their LBP, the types of treatment which were used and their satisfaction with the treatments. An inductive qualitative approach was selected to enable women to describe the impact of pregnancy related LBP and explain their (non)-treatment seeking rationales from their own perspectives [15].

\subsection{Procedures}

The questionnaire was completed via a structured interview, conducted by the researchers, in a private room in the post-natal clinics and took approximately 10 minutes to complete. All women who reported LBP during pregnancy ( $n=71$ ) were then individu- 
Table 1

Characterisation of the sample

\begin{tabular}{|c|c|}
\hline Variables & $\mathrm{M} \pm \mathrm{SD}$ \\
\hline Age (years) & $29.7 \pm 4.5$ \\
\hline Pregnancy duration (weeks) & $38.7 \pm 1.5$ \\
\hline \multicolumn{2}{|l|}{ Weight $(\mathrm{kg})$} \\
\hline Before pregnancy & $62.2 \pm 11.1$ \\
\hline After pregnancy & $75.1 \pm 11.2$ \\
\hline \multicolumn{2}{|l|}{ Body mass index $\left(\mathrm{kg} / \mathrm{m}^{2}\right)$} \\
\hline Before pregnancy & $24.2 \pm 4.6$ \\
\hline After pregnancy & $29.2 \pm 5.0$ \\
\hline Variables & $\mathrm{n}(\%)$ \\
\hline \multicolumn{2}{|l|}{ Marital status } \\
\hline Single & $21(20.0)$ \\
\hline Married or living with a partner & $79(75.2)$ \\
\hline Divorced & $5(4.8)$ \\
\hline \multicolumn{2}{|l|}{ Profession } \\
\hline Primary sector & $0(0)$ \\
\hline Secondary sector & $14(13.3)$ \\
\hline Tertiary sector & $68(64.8)$ \\
\hline Student & $3(2.9)$ \\
\hline Housewife & $4(3.8)$ \\
\hline Unemployed & $16(15.2)$ \\
\hline \multicolumn{2}{|l|}{ Parity } \\
\hline Primiparous & $58(55.2)$ \\
\hline Multiparous & $47(44.8)$ \\
\hline \multicolumn{2}{|l|}{ Abdominal or low back surgery } \\
\hline Yes & $3(2.9)$ \\
\hline No & $102(97.1)$ \\
\hline \multicolumn{2}{|l|}{ Presence of an illness condition } \\
\hline Yes & $13(12.4)$ \\
\hline No & $92(87.6)$ \\
\hline \multicolumn{2}{|l|}{ LBP in previous pregnancies } \\
\hline Yes & $25(53.2)$ \\
\hline No & $22(46.8)$ \\
\hline \multicolumn{2}{|c|}{ Trimester of LBP appearance in the last pregnancy } \\
\hline First & $1(1.4)$ \\
\hline Second & $2(2.8)$ \\
\hline Third & $39(54.9)$ \\
\hline All trimesters & $5(7)$ \\
\hline More than one trimester & $24(33.8)$ \\
\hline \multicolumn{2}{|l|}{ Location of pain irradiation with LBP } \\
\hline Buttock & $4(13.8)$ \\
\hline Thigh & $5(17.2)$ \\
\hline Leg & $5(17.8)$ \\
\hline Abdomen & $4(13.8)$ \\
\hline More than one option & $11(36.9)$ \\
\hline
\end{tabular}

M: Mean; SD: standard deviation.

ally interviewed by one of two researchers (previously trained in the interviews). The interview also lasted for approximately 10 minutes due to time limitation.

\subsection{Data analyses}

Descriptive statistics (mean \pm standard deviation) were used to describe the sample. Mann-Whitney U test was used to study statistical differences between primiparous and multiparous women with and without LBP for: age, weight, body mass index and pregnancy duration. Fisher's exact test was conducted to investigate the relationship between primiparous and multiparous women with LBP and: i) their pain, i.e., frequency, intensity, duration, and irradiation and ii) the impact of LBP on their daily life during pregnancy, i.e., worsening with advance of pregnancy, sleep disturbances, prevented daily activities and LBP treatments. All analyses were performed using Statistical Package for Social Sciences version 15.0 (SPSS, Inc. Chicago, IL, USA) with a level of significance of 0.05 .

The interviews were transcribed and subjected to content analysis by 2 independent assessors. The interview transcripts were read repeatedly by two of the authors ( $2^{\text {nd }}$ and $3^{\text {rd }}$ authors) that acted as independent judges who i) constructed a sense of the text as a whole, ii) identified meaning units according to the aim of the study and iii) condensed the meaning units and clustered them into major categories. Thereafter, a formal meeting was held to compare individual analysis and to agree on final categories and subcategories. Critical feedback was provided by the fourth author [16].

\section{Results}

\subsection{Sample characterisation}

On average participants were $29.7 \pm 4.5$ years old had a normal duration of pregnancy $38.7 \pm 1.5$ weeks, weighed of $62.2 \pm 11.1 \mathrm{~kg}$ before and $75.1 \pm 11.2$ $\mathrm{kg}$ after pregnancy, respectively, and had a body mass index before $24.2 \pm 4.6 \mathrm{~kg} / \mathrm{m}^{2}$ and after pregnancy of $29.2 \pm 5.0 \mathrm{~kg} / \mathrm{m}^{2}$, respectively.

Three quarters of these women were married or living with a partner and most of them worked in a tertiary $\operatorname{sector}^{1}(64.8 \%)$. Fifty-eight women were primiparous (55.2\%) and forty-seven were multiparous (44.8\%). Twenty five women (53.2\%) had LBP in previous pregnancies. Most women (from 105), did not have previous abdominal or low back surgery $(97.1 \%)$ and neither had any $(87.6 \%)$ relevant pathology (such as arterial hypertension, diabetes and obesity) before pregnancy. LBP was most common in the third trimester $(n=39 ; 54.9 \%)$ however; about one third of the sample $(n=24 ; 33.8 \%)$ reported LBP occuring in more than one trimester. In most cases, the pain did not radiate, however, when irradiation occurred it affected the

\footnotetext{
${ }^{1}$ Tertiary sector is defined as a sector of production outside of agriculture and industry and includes construction, trade, finance, real estate, private services, government and sometimes transportation.
} 
Table 2

Characterisation of primiparous and multiparous women with or without LBP during pregnancy

\begin{tabular}{|c|c|c|c|c|}
\hline & \multicolumn{2}{|c|}{ With LBP $(n=71)$} & \multicolumn{2}{|c|}{ Without LBP $(n=34)$} \\
\hline & $\begin{array}{c}\mathrm{P}(n=40) \\
\mathrm{M} \pm \mathrm{SD}\end{array}$ & $\begin{array}{c}\mathrm{M}(n=31) \\
\mathrm{M} \pm \mathrm{SD}\end{array}$ & $\begin{array}{c}\mathrm{P}(n=18) \\
\mathrm{M} \pm \mathrm{SD}\end{array}$ & $\begin{array}{c}\mathrm{M}(n=16) \\
\mathrm{M} \pm \mathrm{SD}\end{array}$ \\
\hline Age (years) & $27.6 \pm 4.1^{*}$ & $31.1 \pm 4.3^{*}$ & $29.8 \pm 4.8$ & $31.9 \pm 3.1$ \\
\hline Pregnancy duration (weeks) & $38.3 \pm 1.8$ & $38.9 \pm 1.3$ & $38.6 \pm 1.5$ & $39.2 \pm 0.9$ \\
\hline \multicolumn{5}{|l|}{ Weight $(\mathrm{kg})$} \\
\hline Before pregnancy & $61.9 \pm 10.7$ & $63.2 \pm 13.6$ & $60.5 \pm 8.7$ & $62.8 \pm 9.3$ \\
\hline End of pregnancy & $75.9 \pm 11.7$ & $75.3 \pm 12.6$ & $73.1 \pm 8.8$ & $74.6 \pm 10.4$ \\
\hline \multicolumn{5}{|l|}{ Body mass index $\left(\mathrm{Kg} / \mathrm{m}^{2}\right)$} \\
\hline Before pregnancy & $24.3 \pm 4.5$ & $24.4 \pm 5.7$ & $23.4 \pm 3.1$ & $24.2 \pm 4.2$ \\
\hline End of pregnancy & $29.9 \pm 5.5$ & $29.1 \pm 5.5$ & $28.3 \pm 3.1$ & $28.8 \pm 4.6$ \\
\hline
\end{tabular}

P: primiparous; M: multiparous; Mean $(\mathrm{M}) \pm$ standard deviation (SD); ${ }^{*}$ Mann-Whitney U test $(p=0.001)$.

Table 3

Characterisation of primiparous $(n=40)$ and multiparous $(n=31)$ women with LBP during pregnancy

\begin{tabular}{|c|c|c|c|}
\hline & Primiparous $\mathrm{n}(\%)$ & Multiparous $\mathrm{n}(\%)$ & $\mathrm{p}$ \\
\hline \multicolumn{4}{|l|}{ Pain frequency } \\
\hline Daily & $25(62.5)$ & $20(64.5)$ & 1.000 \\
\hline Weekly & $10(25.0)$ & $7(22.6)$ & \\
\hline Bimonthly & $5(12.5)$ & $4(12.9)$ & \\
\hline \multicolumn{4}{|l|}{ Pain intensity } \\
\hline Mild & $7(17.5)$ & $7(22.6)$ & 0.075 \\
\hline Moderate & $26(65.0)$ & $12(38.7)$ & \\
\hline Severe & $7(17.5)$ & $11(35.5)$ & \\
\hline \multicolumn{4}{|l|}{ Pain duration } \\
\hline$<1$ hour & $11(27.5)$ & $6(19.4)$ & 0.725 \\
\hline$[1 ; 2]$ hours & $5(12.5)$ & $5(16.1)$ & \\
\hline$>2$ hours & $21(52.5)$ & $19(61.3)$ & \\
\hline \multicolumn{4}{|l|}{ Pain irradiation } \\
\hline Yes & $15(37.5)$ & $14(45.2)$ & 0.628 \\
\hline No & $25(62.5)$ & $17(54.8)$ & \\
\hline \multicolumn{4}{|c|}{ Worsening with pregnancy advance } \\
\hline Yes & $30(75.0)$ & $25(80.6)$ & 0.775 \\
\hline No & $10(25.0)$ & $6(19.4)$ & \\
\hline \multicolumn{4}{|c|}{ Sleep disturbances } \\
\hline Yes & $20(50.0)$ & $24(77.4)$ & $0.026^{*}$ \\
\hline No & $20(50.0)$ & $7(22.6)$ & \\
\hline \multicolumn{4}{|c|}{ LBP prevented daily activities } \\
\hline Yes & $22(55.0)$ & $19(61.3)$ & 0.635 \\
\hline No & $18(45.0)$ & $12(38.7)$ & \\
\hline \multicolumn{4}{|l|}{ LBP treatment } \\
\hline Yes & $3(7.5)$ & $2(6.5)$ & 1.000 \\
\hline No & $37(92.5)$ & $29(93.5)$ & \\
\hline
\end{tabular}

*Fisher's exact test.

thigh ( $n=5 ; 17.2 \%)$; the leg $(n=5 ; 17.8 \%)$ or more than one specific location $(n=11 ; 36.9 \%)$ and Table 1 provides a detailed sample characterization.

\subsection{Characterisation of $L B P$ during pregnancy}

LBP was reported by $67.6 \%(n=71)$ of all women, divided in primiparous $56.3 \%(n=40)$ and multiparous $43.7 \%(n=31)$. Age was significantly different between primiparous and multiparous women with LBP ( $p=0.001)$, but not in those without LBP. No other statistically significant differences between primiparous and multiparous women (with and without LBP) were found (Table 2).

For those variables relating only to the women with LBP (Table 3), the majority of both primi- and multiparous women reported daily pain $(n=25 ; 62.5 \%$ primiparous and $n=20 ; 64.5 \%$ multiparous). Regarding pain intensity, most primiparous reported as moderate $(n=26 ; 65 \%)$ whereas multiparous reported as moderate $(n=12 ; 38.7 \%)$ and severe $(n=11$; $35.5 \%)$. In both groups the pain lasted for more than 2 hours $(n=21 ; 52.5 \% ; n=19 ; 61.3 \%)$ and in most cases, the pain did not radiate $(n=25 ; 62.5 \% ; n=17$; 
Table 4

Relief and worsening factors of primiparous $(n=40)$ and multiparous $(n=31)$ women with LBP during pregnancy

\begin{tabular}{lcc}
\hline & Primiparous $\mathrm{n}(\%)$ & Multiparous $\mathrm{n}(\%)$ \\
\hline Relief strategies & & $11(35.5)$ \\
Rest & $20(50.0)$ & $2(6.5)$ \\
Medication & $1(2.5)$ & $2(6.5)$ \\
Massage & $3(7.5)$ & $0(0.0)$ \\
Specific exercises & $1(2.5)$ & $12(38.7)$ \\
Used more than relief strategy(ies) & $11(27.5)$ & $4(12.9)$ \\
Used other relief strategy & $4(10.0)$ & $4(12.9)$ \\
Worsening factors & $5(12.5)$ & $3(9.7)$ \\
Daily activities & $2(5.0)$ & $3(9.7)$ \\
Bad posture & $3(7.5)$ & $4(12.9)$ \\
Sitting for a long time $(>2$ hours) & $6(15.0)$ & $17(54.8)$ \\
Standing for a long time $(>2$ hours) & $22(55.0)$ & $0(0.0)$ \\
More than one worsening factor & $2(5.0)$ & \\
Other worsening factor(s) & & \\
\hline
\end{tabular}

$54.8 \%$ ). Most women reported that their pain severity increased as the pregnancy progressed $(n=30 ; 75.0 \%$; $n=25 ; 80.6 \%)$ and over half of the sample $(n=22$; $55.0 \% ; n=19 ; 61.3 \%$ ) also reported a negative impact on their ability to perform daily activities. Sleep disturbance was an issue for both groups ( $n=20,50 \%$; $n=$ $24,77.4 \%$ ) but was statistically more common in multiparous women $(p=0.026)$. No other significant differences between primiparous and multiparous women with LBP were found. Despite the frequency and severity of LBP during pregnancy, very few women $(n=$ $3,7.5 \% ; n=2,6.5 \%$ ) received any treatment. Table 4 presents the reported factors which relieved and exacerbated the women's LBP. These factors were generally similar between the two groups. Rest was the most frequently reported factor for relieving pain in over $50.0 \%(n=20)$ of primiparous and $35.5 \%(n=$ 11 ) of multiparous women. Performing daily activities ( $n=5,12.5 \% ; n=4,12.9 \%$ ) and standing for long periods of time $(n=6,15.0 \% ; n=4,12.9 \%)$ were the most commonly reported aggravating factors. For both groups, a combination of these factors was commonly reported $(n=22,55.0 \% ; n=17,54.8 \%$ ).

\subsection{Interview findings}

All women who reported LBP during pregnancy $(n=71)$ were interviewed. Only five of these $(7.0 \%)$ had received any treatment for LBP. Three were treated with daily medication and two were treated with physiotherapy, which had been on the recommendation of friends or colleagues, not of a health professional. Physiotherapy treatments consisted of massage, electrotherapy, ice, ultrasound and heat and were performed daily or weekly. Both women who received physiotherapy were highly satisfied with their LBP treatment, i.e., for one, pain was relieved completely and another reported substantial relief. Of the sixtysix women (93.0\%) with LBP who did not receive any treatment only fourteen $(21.2 \%)$ had consulted their doctors.

\subsubsection{Seeking treatment}

None of the pregnant women who consulted their general practitioner $(n=14)$ about LBP were referred to physiotherapy or any other treatments. Ten women $(41.7 \%)$ did not consult a physiotherapist but were advised by friends and family to use physiotherapy pain relief strategies such as massage, rest, use of a pelvic belt and posture correction.

\subsubsection{Not seeking treatment}

Forty-two women $(63.6 \%)$ did not seek any treatment: eighteen $(42.9 \%)$ because their pain was mild or infrequent; ten $(23.8 \%)$ believed that LBP was normal during pregnancy, whilst eight $(19 \%)$ were unaware that there were any treatments available for LBP related to pregnancy. Other reasons such as lack of time, being afraid of treatment while pregnant and unawareness of LBP as a disease were also reported by six women $(14.3 \%)$.

\subsubsection{Impact on women's lives}

Low back pain had a major impact on the daily lives of pregnant women. Thirty five women (49.3\%) reported increased difficulties performing household chores, such as cleaning rooms, vacuum cleaning and lifting heavy loads. They felt slower, needed to rest more often and were unable to maintain sustained postures such as standing or sitting. Five women (7\%) also reported difficulties at work; four of these $(6 \%)$ were on sick leave because of LBP. Five (7\%) of the women 
felt more tired, four (6\%) slept badly, and two (3\%) had difficulty whilst walking. Only $22.5 \%$ of women ( $n=16$ ) indicated no meaningful impact of LBP on their daily activities.

\section{Discussion}

As in previous studies [1-4], our findings identify the high prevalence of LBP (67.6\%) amongst pregnant women. Our data, collected with a sample with similar socio-demographic and obstetric characteristics [1], highlighted the impact of LBP on women's lives and the current lack of treatment seeking and treatment provision for these symptoms. The data also reinforced the complexity of LBP in terms of the potential aggravating or causative factors during pregnancy.

In our study and in line with what it has been reported previously, the prevalence of LBP increased as pregnancy progressed $\left(54.9 \%-3^{\text {rd }}\right.$ trimester $)$. For many, the impact of LBP was substantial, with the majority reporting daily pain of moderate to severe intensity which lasted for more than 2 hours. Their pain was mainly relieved with rest and worsened with the progression of the pregnancy, causing sleep disturbances and preventing the performance of daily activities, independently of parity. It also impacted on their work productivity: women needed to rest more often to relieve pain, experienced increased fatigue and took more sick leave. The evidence for the impact of professional role on pregnancy related LBP is equivocal. Orvieto et al. [2] reported increased LBP in pregnant women who were exposed to heavier physical work, such as repetitive lifting and bending; whilst Turgut et al. [17] found no relationship between professional role and the incidence of pregnancy related LBP. The majority of women in this study worked in the tertiary sector $(64.8 \%)$ generally undertaking roles involving light physical activity. However, these roles typically involve static postures which was a factor reported to aggravate LBP [18].

Parity has also been identified as a risk factor for developing LBP during pregnancy [5]. However, in this study LBP characteristics were found to be generally similar between primiparous and multiparous women, except for sleep disturbances $(p=0.026)$ which were reported more commonly by multiparous women. Multiparous women might be woken by their children and therefore be more aware of pain at night.

Few women sought treatment, although LBP impacted highly on daily activities. There were several reasons given for not seeking treatment: mild intensity or low frequency of pain, absence of health professional referral, believing that LBP is normal during pregnancy, use of other relief strategies and lack of awareness of possible treatments. However, physiotherapy is an effective treatment for LBP during pregnancy [13], and referral should be considered to prevent or reduce LBP and enhance the quality of life of pregnant women.

Several limitations of this study need to be acknowledged. The study was conducted in settings where only post-partum medical appointments occurred and a small sample size was used which could have biased these results. Therefore, the results should be interpreted with caution, as this was a convenience sample. Brief semi-structured interviews enabled description of the reasoning behind women's treatment seeking behaviours' however depth interviews could clarify the impact of LBP on pregnant women and greater understanding of their concerns about and hopes for treatment. Further qualitative research could further elucidate the experience of living, seeking and receiving treatments for LBP during pregnancy.

\section{Conclusion}

This study showed that LBP related to pregnancy is highly prevalent. Pain intensity, frequency, duration and sleep disturbances caused by LBP during pregnancy have a major impact on pregnant women performing their daily activities, which is worsened with advanced pregnancy.

Despite the prevalence and severity of symptoms LBP was largely untreated due to: i) women's assumptions that LBP during pregnancy was normal or untreatable and ii) a lack of treatment referral (e.g to physiotherapy), advice or prescription by doctors. Few women received physiotherapy treatment and they reported improvements in pain and quality of life. Advice on preventing and treating LBP during pregnancy should be a routine element of pre-natal care and onward referral to physiotherapy should be considered for those with persistent symptoms.

\section{References}

[1] Assis RGd, Tibúrcio RES. Prevalência e características da lombalgia na gestação: um estudo entre gestantes assistidas no programa de pré-natal da maternidade Dona Íris em Goiânia. Goiânia: Universidade Católica de Goiás, 2004. 
[2] Orvieto R, Anat A, Ben-Rafael Z, Gelernter I, Achiron R. Low-back pain of pregnancy Acta Obstetricia et Gynecologica Scandinavica. 1994; 73(3): 209-14. doi: 10.3109/00016 349409023441.

[3] Sabino J, Grauer JN. Pregnancy and low back pain. Current Reviews in Musculoskeletal Medicine. 2008; 1(2): 137-41. doi: 10.1007/s12178-008-9021-8.

[4] Stuge B, Hilde G, Vollestad N. Physical Therapy for pregnancy-related low back and pelvic pain: A systematic review. Acta obstetricia et gynecologica Scandinavica. 2003; 82(11): 983-90. doi: 10.1034/j.1600-0412.2003.00125.x.

[5] Mogren I, Pohjanen A. Low back pain and pelvic pain during pregnancy: prevalence and risk factors. Spine. 2005; 30(8): 983-91. doi: 10.1097/01.brs.0000158957.42198.8e.

[6] Pennick V, Young G. Interventions for preventing and treating pelvic and back pain in pregnancy. Cochrane Database of Systematic Reviews. 2007(2). doi: 10.1002/14651858.

[7] Garshasbi A, Zadeh SF. The effect of exercise on the intensity of low back pain in pregnant women. International journal of gynecology and obstetrics. 2005; 88(3): 271-5. doi: 10.1016/ j.ijgo.2004.12.001.

[8] Kihlstrand M, Stenman B, Nilsson S, Axelsson O. Watergymnastics reduced the intensity of back/low back pain in pregnant women. Acta Obstetricia et Gynecologica Scandinavica. 1999; 78(3): 180-5. doi: 10.1034/j.1600-0412.1999. 780302.x.

[9] Shim M-J, Leeb Y-S, Ohc H-E, Kimc J-S. Effects of a backpain-reducing program during pregnancy for Korean women: A non-equivalent control-group pretest-posttest study. International Journal of Nursing Studies. 2007; 44(1): 19-28. doi: 10.1016/j.ijnurstu.2005.11.016.

[10] Field T, Hernandez-Reif M, Hart S, Theakston H, Schanberg $\mathrm{S}$, Kuhn C. Pregnant women benefit from massage therapy. Journal of psychosomatic obstetrics and gynecology. 1999; 20(1): 31-8. doi: 10.3109/01674829909075574.
[11] Carr C. Use of maternity support binder for relief of pregnancy-related back pain. Journal of obstetric, gynecologic and neonatal nursing. 2003; 32(4): 495-502. doi: 10.1177/ 0884217503255196.

[12] Coldron Y, Crothers E, Haslam J, Notcutt W, Sidney D, Thomas R, et al. ACPWH guidance on the safe use of Transcutaneous Electrical Nerve Stimulation (TENS) for musculosketal pain during pregnancy. Reino Unido: The Association of Chartered Physiotherapists in Women's Health; 2007 [22 de Outubro de 2008]; Available from: http://www.oaaanaes.ac.uk/assets/_managed/editor/File/PDF/info_for_moth ers/TENS\%20Statement\%20JUNE\%2007\%20ACPWH $\% 20$ Final.pdf.

[13] Vleeming A, Albert HB, Östgaard HC, Sturesson B, Stuge B. European guidelines for the diagnosis and treatment of pelvic girdle pain. European Spine Journal. 2008; 17(6): 794-819. doi: 10.1007/s00586-008-0602-4.

[14] Bland JM, Altman DG. Statistical notes: Cronbach's alpha. British Medical Journal 1997; 314(7080): 572. doi: 10.1136/ bmj.314.7080.572.

[15] Margarete S, Jennifer L. Writing usable qualitative health research findings. Qualitative Health Research. 2012; 22(10): 1404-13. doi: 10.1177/1049732312450368.

[16] Pope C, Mays N. Reaching the parts other methods cannot reach: An introduction to qualitative methods in health and health services research. British Medical Journal 1995; 311(6996): 42-5. doi: 10.1136/bmj.311.6996.42.

17] Turgut F, Turgut M, Ccetinsahin M. A prospective study of persistent back pain after pregnancy. European journal of obstetrics \& gynecology and reproductive biology. 1998; 80(1): 45-8. doi: 10.1016/S0301-2115(98)00080-3.

[18] Wang S-M, Dezinno P, Maranets I, Berman MR, CaldwellAndrews AA, Kain ZN. Low back pain during pregnancy: prevalence, risk factors, and outcomes. American college of obstetricians and gynecologists. 2004; 104(1): 65-70. doi: 10.1097/01.AOG.0000129403.54061.0e. 